University of Nebraska - Lincoln

DigitalCommons@University of Nebraska - Lincoln

Agronomy \& Horticulture - Faculty Publications

Agronomy and Horticulture Department

2016

\title{
Smokey comes of age: unmanned aerial systems for fire management
}

\author{
Dirac L. Twidwell Jr. \\ University of Nebraska-Lincoln, dirac.twidwell@unl.edu \\ Craig R. Allen \\ US Geological Survey-Nebraska Cooperative Fish and Wildlife Research Unit, callen3@unl.edu \\ Carrick Detweiler \\ University of Nebraska-Lincoln, cdetweiler2@unl.edu \\ James Higgins \\ University of Nebraska-Lincoln \\ Christian Laney \\ University of Nebraska-Lincoln
}

See next page for additional authors

Follow this and additional works at: https://digitalcommons.unl.edu/agronomyfacpub

Part of the Agricultural Science Commons, Agriculture Commons, Agronomy and Crop Sciences Commons, Botany Commons, Horticulture Commons, Other Plant Sciences Commons, and the Plant Biology Commons

Twidwell, Dirac L. Jr.; Allen, Craig R.; Detweiler, Carrick; Higgins, James; Laney, Christian; and Elbaum, Sebastian, "Smokey comes of age: unmanned aerial systems for fire management" (2016). Agronomy \& Horticulture -- Faculty Publications. 983.

https://digitalcommons.unl.edu/agronomyfacpub/983

This Article is brought to you for free and open access by the Agronomy and Horticulture Department at DigitalCommons@University of Nebraska - Lincoln. It has been accepted for inclusion in Agronomy \& Horticulture -Faculty Publications by an authorized administrator of DigitalCommons@University of Nebraska - Lincoln. 


\section{Authors}

Dirac L. Twidwell Jr., Craig R. Allen, Carrick Detweiler, James Higgins, Christian Laney, and Sebastian Elbaum 


\title{
Smokey comes of age: unmanned aerial systems for fire management
}

\author{
Dirac Twidwell ${ }^{1 *}$, Craig R Allen², Carrick Detweiler ${ }^{3}$, James Higgins ${ }^{3}$, Christian Laney ${ }^{3}$, and Sebastian Elbaum ${ }^{3}$
}

During the past century, fire management has focused on techniques both to protect human communities from catastrophic wildfire and to maintain fire-dependent ecological systems. However, despite a large and increasing allocation of resources and personnel to achieve these goals, fire management objectives at regional to global scales are not being met. Current fire management techniques are clearly inadequate for the challenges faced by fire managers, and technological innovations are needed. Advances in unmanned aerial systems (UAS) technology provide opportunities for innovation in fire management and science. In many countries, fire management organizations are beginning to explore the potential of UAS for monitoring fires. We have taken the next step and developed a prototype that can precisely ignite fires as part of wildfire suppression tactics or prescribed fires (fire intentionally ignited within predetermined conditions to reduce hazardous fuels, improve habitat, or mitigate for large wildfires). We discuss the potential for these technologies to benefit fire management activities, while acknowledging the sizeable sociopolitical barriers that prevent their immediate broad application.

Front Ecol Environ 2016; 14(6): 333-339, doi:10.1002/fee.1299

Since the onset of the Industrial Revolution, calls for innovation in fire management are the result of a continued inability to coexist with fire (Bowman et al. 2009). For tens of thousands of years, in many regions of the world, humans deliberately ignited fires to manipulate nature for their benefit, thereby increasing the occurrence of fires and their impacts as an ecological and evolutionary process (Bowman et al. 2011; McWethy et al. 2013). The opposite is true today. Fire management professionals are pressured to meet the often conflicting need to control wildfires to protect lives and property (Figure 1a), while also igniting prescribed fires (any fire intentionally ignited within predetermined conditions to

\section{In a nutshell:}

- Technological innovations are needed to help advance fire management

- Promising applications of UAS (or drone-based) technology that support firefighting and prescribed fire (controlled burning) operations are emerging

- The application of UAS technology for wildfire management and the conservation of fire-dependent ecosystems has great potential benefits but there are also barriers to their use

- We envision a future where a swarm of autonomous and interacting UAS conducts fire management and wildfire suppression operations, reducing risks and costs while enhancing capabilities

${ }^{1}$ Department of Agronomy and Horticulture, University of Nebraska-Lincoln (UNL), Lincoln, NE*(dirac.twidwell@unl.edu); ${ }^{2}$ US Geological Survey-Nebraska Cooperative Fish and Wildlife Research Unit, UNL, Lincoln, NE; ${ }^{3}$ Department of Computer Science and Engineering, UNL, Lincoln, NE reduce hazardous fuels, improve habitat, or mitigate for large wildfires; Figure 1b). Yet, despite good intentions and billions of dollars invested, large wildfires are becoming more common (Flannigan et al. 2009), and the costs of fighting wildfires are escalating (Calkin et al. 2015). With regard to wildfire suppression, US federal agencies spent US\$15 billion from 2006-2015, which was more than the total amount of money expended on similar efforts in the previous 20 years (NIFC nd). Risk aversion is increasing among agencies that have historically provided proactive fire management (DellaSala et al. 2004; Hawbaker et al. 2013), and some federal agencies in the US have now established internal policies that prevent their personnel from direct involvement with prescribed fires conducted on private lands (Twidwell et al. 2015). Such aversions have produced more limited fire prescriptions, with the pathological effect of creating evertightening windows of meteorological and environmental conditions under which deliberate ignitions are allowed (Twidwell et al. 2016). As a result, prescribed fires are rarely conducted in conditions that mimic the dynamics of historical fire regimes (Twidwell et al. 2016), resulting in declines of many floral and faunal specialists (eg Smucker et al. 2005; Hutto 2008; van Wilgen 2013) and failure to prevent or reverse undesirable state transitions (eg from grassland to shrubland or woodland; Bond et al. 2005; Twidwell et al. 2013a).

Advances in unmanned aerial systems (UAS) technology provide opportunities for innovation in fire management and science. Wildland firefighting and prescribed fire operations have long relied on manned aerial vehicles or ground crews for monitoring, ignition, and suppression, which carry inherent risks to human life. Manned aviation-related fatalities account for $26 \%$ of all firefighter 

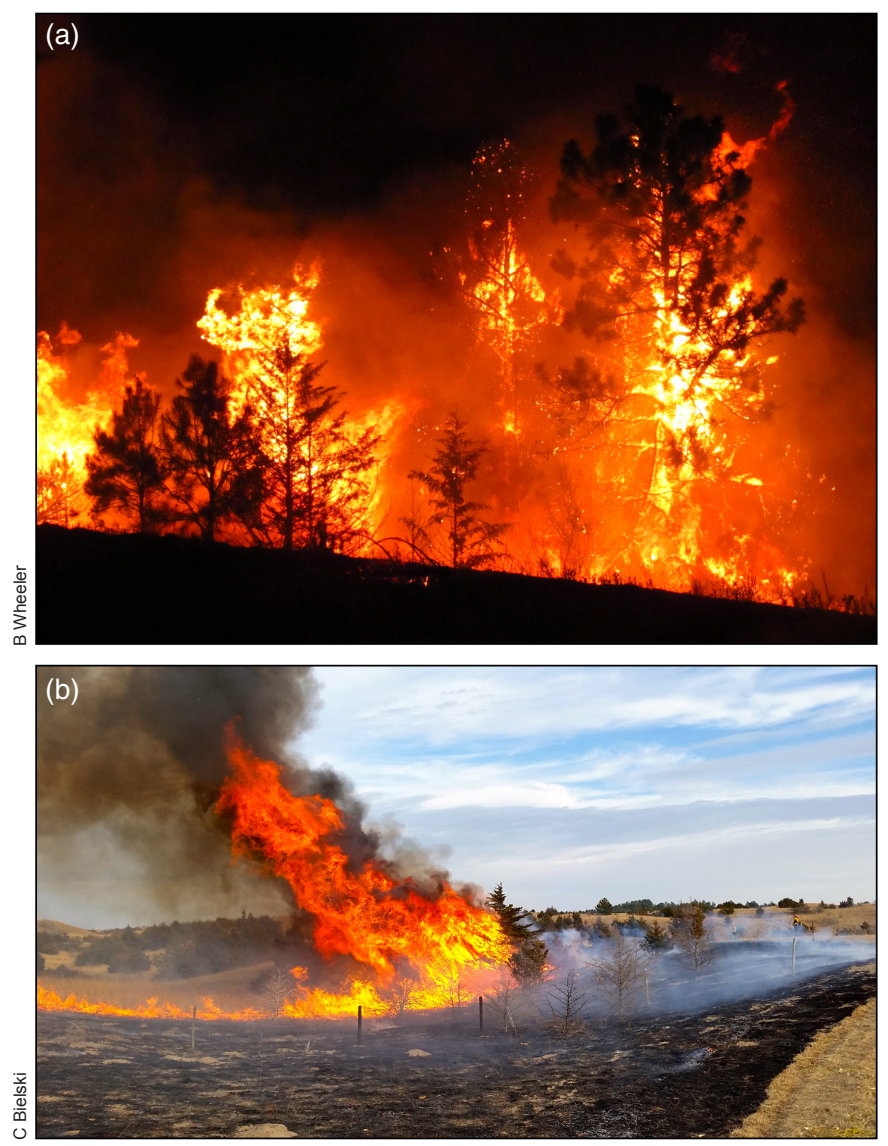

Figure 1. Fire management professionals are tasked with both putting out uncontrollable wildfires that threaten lives, homes, and infrastructure, while also igniting fires under specific prescriptions to sustain fire-dependent resources. Shown here are (a) a wildfire in 2012 burning through ponderosa pine (Pinus ponderosa) forest invaded in the understory by eastern redcedar (Juniperus virginiana) on the Niobrara Valley Preserve in north-central Nebraska, and (b) a prescribed fire on the same property in 2015 to restore Sandhills grassland following invasion of eastern redcedar.

deaths in the US since 2000 (Butler et al. 2015). Wildfire tragedies, such as the Yarnell Hill Wildfire in Arizona that killed 19 elite wildland firefighters, have heightened awareness of the risks to suppression crews. Wildfire management costs now account for over $50 \%$ of the US Forest Service (USFS) budget (Topik 2015), depleting funds that previously supported scientific investigations meant to enhance fire management. In the past few years, the USFS has been exploring UAS to reduce the risks and costs associated with fire monitoring operations (USFS 2015). Recently, we developed a UAS prototype for conducting fire ignitions - currently a limiting factor in wildfire suppression operations that "fight fire with fire", and as part of prescribed fire operations needed to conserve many grassland, savanna, and forest ecosystems. Here, we discuss the potential uses of UAS technology in fire management, in the context of current operational and institutional barriers that preclude broader UAS applications.

\section{Expanding UAS applications into fire management}

\section{Wildfire planning and monitoring}

The use of UAS in wildfire planning and monitoring has already begun (Figure 2). In 2013, the USFS used a UAS from the US Department of Defense for 24-hour monitoring of the California Rim Fire. Multiple benefits of using UAS to support incidence awareness and assessment were reported: earlier spotfire detection (detection of new fires ignited outside the perimeter of the main fire by flying sparks or embers) and suppression than possible with ground crews; improved allocation of personnel and resources by avoiding false identification of new fires; continuous mapping of a fire's perimeter, size, spread, and intensity; and enhanced visibility in high smoke and low light conditions. Additional UAS applications for wildland fire monitoring include flights being approved to monitor large wildfires in the US Pacific Northwest and near the Perth metropolitan complex in Australia (Werner 2015). Furthermore, because cellular phone service and radio relay stations are often inadequate in remote areas, precluding timely transmissions on changing fire conditions that pose safety concerns to ground personnel, UAS can also be equipped with radio relays or cellular transmission capabilities to improve communications.

Advances in UAS technology are expected to expand the utility of unmanned technology into the planning and monitoring of wildfire and prescribed fires (USFS 2015). The USFS has identified ways to use UAS to monitor ground crews in low visibility conditions and to respond faster to changes in fire movement and behavior. UAS can identify locations of existing or potential fire breaks, water sources available for restocking vehicles (including helicopters), monitor weather and air-quality conditions, as well as prioritize firefighting tactics by assessing fuels around homes or infrastructure ahead of the fire. Because of their low cost, flexibility, and high spatiotemporal resolution, UAS remote-sensing platforms are being used to fill data gaps and supplement the efforts of manned aircraft and remote-sensing systems (Tang and Shao 2015). This has resulted in considerable research on the potential for UAS to map wildland fuels (Everaerts 2008; Merino et al. 2012). Equipping UAS with thermal imaging or electro-optical cameras provides agency personnel responsible for managing wildfires with more continuous monitoring of fire size, intensity, and movement, as well as rate of spread (USFS 2015). Such data would also provide scientists with fine-scale information on fire behavior that could be used to validate and improve fire models. This would be especially valuable to fire modelers in grassland and shrubland environments, where tree canopies do not obstruct UAS operation and imagery. Scientists have been calling for improved technologies to help quantify the fine-scale 
variability in fuels and fires and the differential responses exhibited by organisms responding to fire events in these ecosystems (Twidwell et al. 2009; Gagnon et al. 2015; Oliveira et al. 2015).

\section{Monitoring prescribed fires}

We foresee that advances in UAS technology will help to improve monitoring wildfire behavior, weather conditions, and smoke associated with prescribed burning operations. Practitioners of prescribed burns cite a lack of resources as a major hindrance for conducting their operations and meeting their resource objectives (Weir 2009). Considering that the amount of funds allocated to wildfire response and suppression is growing, the resources for prescribed fire are expected to remain limited and restricted funding will continue to pose challenges for natural resource managers using fire prescriptions (Moritz et al. 2014; Topik 2015).

Innovations in UAS technology have the potential to alleviate personnel limitations. As compared with onthe-ground personnel, UAS can cover more of the fire perimeter and more effectively monitor areas with dense smoke. UAS can therefore reduce or eliminate the need to position personnel in dense smoke areas close to fire fronts (Figure 3), which is a common but undesirable practice used in an attempt to monitor for spotfires when initially conducting a prescribed burn. Given the lack of resources, UAS allow more efficient positioning of available personnel and more rapid suppression response in the case of an unwanted fire ignition occurring outside the designated burned area. Technology is also becoming affordable enough to allow prescribed fire personnel in the private (non-government) sector to monitor prescribed fires with UAS; indeed, in our experience, UAS are already being used, albeit informally, by such individuals to collect video of prescribed fires. Equipping these UAS with additional technology (eg thermal or electrooptical cameras) and sharing these data with scientists would help to fill current knowledge gaps regarding the spatiotemporal dynamics of fire and associated responses of flora and fauna. Given the uncertainty associated with a range of fire behaviors that typically occur in prescribed fire management (Twidwell et al. 2016), scientists - after analyzing such data - would be better able to provide feedback on how to target the fuels and the weather conditions needed to meet natural resource management objectives, or why certain expectations for fire effects are not met.

\section{Aerial ignition}

We recently developed a UAS to conduct fire ignitions (Figure 4; http://bit.ly/22W7x1T). Fire ignitions are the backbone of prescribed fire operations and wildfire suppression operations, and aerial ignitions via helicopters are important components of the former (to burn many

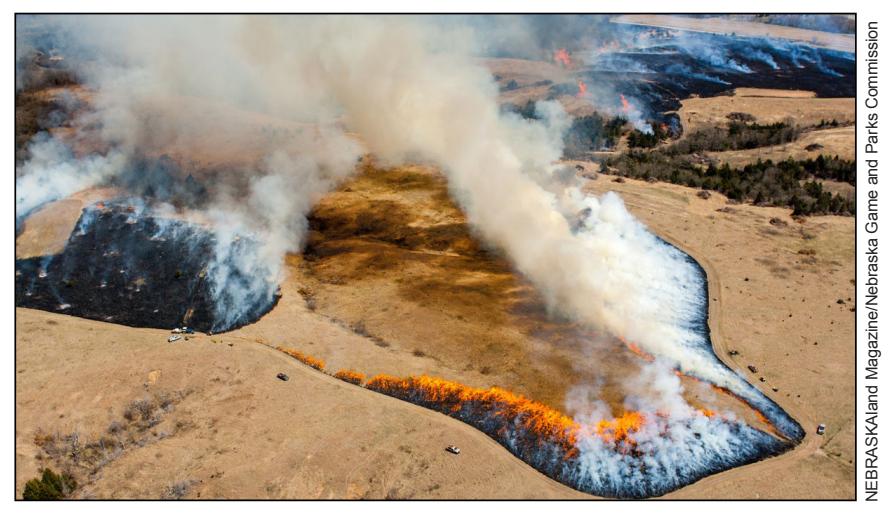

Figure 2. Monitoring large fires aerially is expensive and poses inherent risks to aviators. UAS technology is starting to be used to provide greater monitoring capabilities at reduced costs and with lower risk to human life.

of the planet's largest remaining fire-dependent grassland, savanna, and forest ecosystems) and latter (to "fight fire with fire"). Our initial UAS prototype is light (approximately $1 \mathrm{~kg}$ ), fast (maximum speed of $56 \mathrm{~km}$ per hour [kph]), and portable (can fit in a large backpack). In preliminary experiments at typical flying speeds of $25 \mathrm{kph}$, our prototype - a UAS-FEAT/ FIREMON-integrated (UAS-FFI) vehicle - can traverse several $0.5-\mathrm{km}$-long ignition paths, dropping "dragon eggs" (ping pong ball sized spheres filled with combustible material that are punctured and ignited) every $10 \mathrm{~m}$ (or at other distances, depending on management goals and needs). We suggest that UAS aerial ignition technology has the potential to decrease the risks and costs of helicopter-based aerial ignitions, thereby offering new groups, such as prescribed burners in the private sector, the opportunity to use a type of technology previously limited to agency professionals and wealthy landowners. Insufficient equipment and limited personnel are two primary considerations consistently cited by prescribed burn managers as reasons for not conducting prescribed burns (Weir 2009; Toledo et al. 2013). Our UAS prototype is meant to provide a technological solution to these challenges and sets the stage for more advanced UAS with improved operational characteristics (eg greater flight range, payload size). More detailed specifications of our prototype are provided in WebPanel 1.

UAS-based ignitions also reduce risk exposure among firefighters and prescribed fire practitioners. Fire ignitions have long relied on either positioning ground crews in close proximity to fires or using manned aerial vehicles. The goal of conducting fire ignitions is to strategically ignite fires to control and manipulate the movement and intensity of fire, while also minimizing the potential for embers to start new fires in undesired locations. In prescribed fire operations, a series of fires are ignited under a predetermined range of fuel and weather conditions so as to control those fires within a specified management area. 


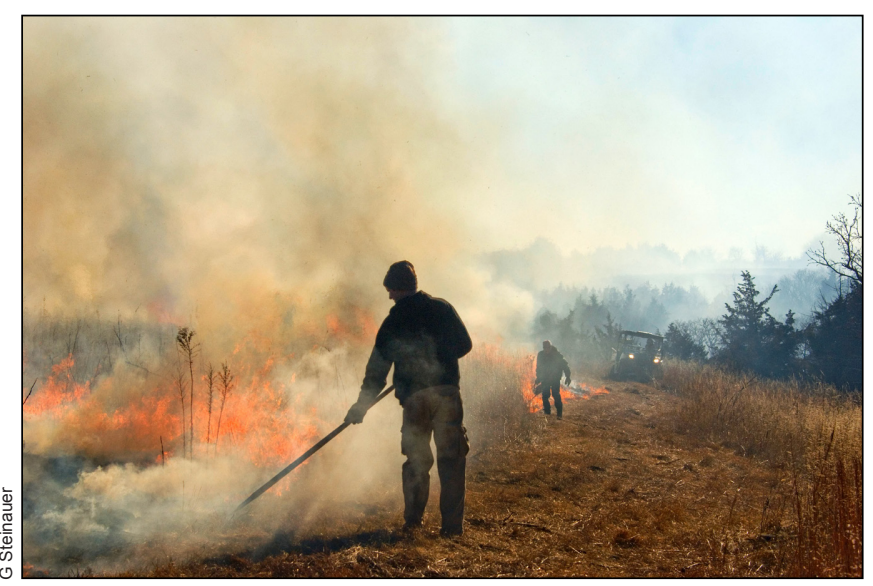

Figure 3. Personnel are often required to "eat smoke" when initially lighting a prescribed fire and monitoring for spotfires outside the area meant to be burned. Monitoring with UAS technology provides "eyes in the sky", thereby improving visibility and removing personnel from dangerous or unhealthy areas.

By way of comparison, in wildfire operations, fire ignitions are used to manage fires that pose risks to people and property, especially during extreme conditions when wildfires cannot be stopped with direct suppression tactics. To accomplish the goals of fire ignition in both scenarios, personnel are sometimes placed within areas that are actively burning. UAS-based fire ignitions can conduct the types of techniques used for interior ignitions, thereby lessening the need to put ground crews in danger. Major causes of firefighter fatalities include all-terrain vehicle accidents; burnover and entrapment; and heat exhaustion (Twidwell et al. 2015). In our initial trials, we used UAS to conduct multi-point source ignitions and to mimic the movement and behavior of fire fronts used in prescribed fire operations by positioning delayed-ignition balls in close proximity to each other (although we acknowledge that these fire fronts are less continuous than those propagated by a continuous ignition source, such as a handheld drip torch).

\section{Institutional and operational barriers to expanding UAS use}

Broadly incorporating UAS technology into fire management will require coordinated efforts that overcome entrenched institutional and operational barriers. Wildfire response agencies have been slow to move past longheld mandates of fire suppression (North et al. 2015). Agency adoption of new technology has been equally slow. In the case of UAS, agencies equate UAS with their manned counterparts. The USFS, for example, places UAS in the same category as manned aircraft and tends to use them as such (USFS 2015). UAS therefore require the same level of pilot certification, vehicle inspection and maintenance, training, and operations in the US as do manned aircraft. The challenge of UAS integration is exacerbated by the existence of multiple organizations that exert control over different components of fire management and aviation, necessitating interagency coordination (IAC 2003). For instance, a Certificate of Authorization (COA) is required from the Federal Aviation Administration (FAA) before UAS operation.

There is still uncertainty regarding the integration of UAS into national airspace. Currently in the US and globally, legal and governance structures pertaining to the environment are relatively inflexible and reactionary, with little ability to rapidly and flexibly cope with changing environments - or to adopt innovations (Garmestani and Allen 2014). Most natural resource law places greater value on predictable certainty in legal frameworks than on anticipatory flexibility, and rightly so in many situations. However, the current legal and governance framework can be a barrier to innovation in an era of global change. For unmanned aerial vehicle technology, the current legal framework is evolving, which fosters uncertainty as new users attempt to adopt the technology for new applications.

Because the FAA has yet to finalize rules regarding UAS integration, the only way for commercial or governmental entities to operate UAS now in the US is through waiver processes, such as obtaining COAs or Section 333 Exceptions. The latter are for non-governmental agencies to obtain an exception to operate UAS in the national airspace. Operators under Section 333 still need to obtain COAs from the FAA for specific flight operations. However, government agencies, such as the USFS, can skip the step of applying for a Section 333 Exception and instead apply directly for a COA (USFS 2015). The one benefit for companies that currently possess a Section 333 Exception is that they are granted a "blanket" COA for operations conducted under $200 \mathrm{ft}(\sim 61 \mathrm{~m})$, away from airports and populated areas. Although the process has become better defined over the past few years, uncertainty and complexity in existing and forthcoming rules create barriers that prevent potential users from taking advantage of advances in UAS technology (Vincent et al. 2015). Some countries, like Australia and Canada, have more explicit and easier-to-follow regulations, potentially facilitating early adoption. Canadian regulations include a streamlined process to determine what type of documentation is required, depending on the type of vehicle and usage (Transport Canada 2015). Australia has gone even further, integrating all UAS regulations into one body of legislation (CASR nd).

For the private non-commercial sector, regulatory oversight of UAS for purposes of conducting prescribed fire ignitions has not been explored at all. In the US, FAA regulations differ according to commercial or recreational usage of UAS. Neither category clearly applies to aerial ignitions conducted by members of the private sector. At present, the FAA requires only that private citizens register their UAS (FAA 2015). It is unclear then whether UAS-based fire ignitions would fall under local and state/ 
provincial burning laws, as do other tools used to ignite prescribed fires. Some private citizens are therefore likely to operate in this "gray area", and use UAS in a "recreational" context for prescribed burning. Others will attempt to garner the appropriate approval or permit in order to include UAS as a tool for conducting ignitions, which necessitates coordination among multiple governing bodies. This process is likely to frustrate individuals unfamiliar with interagency coordination. Successfully navigating this approval process, given a completely new UAS technology meant to ignite fires, will require cooperation among multiple stakeholders, including individuals from the private sector, technology specialists, aviation experts, natural resource professionals, and regulatory officials.

UAS aerial ignition technology has not yet been tested to determine its situational effectiveness across a wide range of users, fuel types, weather conditions, and remote locations. Field trials are needed to assess the potential to match fire management objectives with ignition procedures.

Integrating UAS aerial ignitions into fire management will apparently be more straightforward in open grassland or savanna settings than in areas with high canopy obstruction. Whether UAS will add capacity to crews burning understory forest vegetation, or what the potential utility of UAS at the wildland-urban interface will be, are yet to be determined. Some managers working on large, intact landscapes may have no real alternative to UAS aerial ignition. Meeting their requirements will likely require additional technological advances over our current lightweight UAS prototype (eg longer battery life; greater payloads). An affordable platform will also need to be developed for UAS aerial ignitions to be accessible to diverse stakeholder groups. We note these challenges because multiple operational considerations will ultimately emerge that are specific to a given user and location. It is unknown, at this point, whether UAS will be helpful in sectors without sufficient resources and personnel, or in what instances operational barriers will limit their usefulness.

A future with UAS as a critical component of fire management will ultimately require more progressive legal frameworks that correspond to current non-stationary views of social-ecological systems, and that are themselves more flexible and adaptable (Craig 2010; Garmestani et al. 2013; Green et al. 2015). Policy and legal frameworks that empower experimentation, adap- (a)

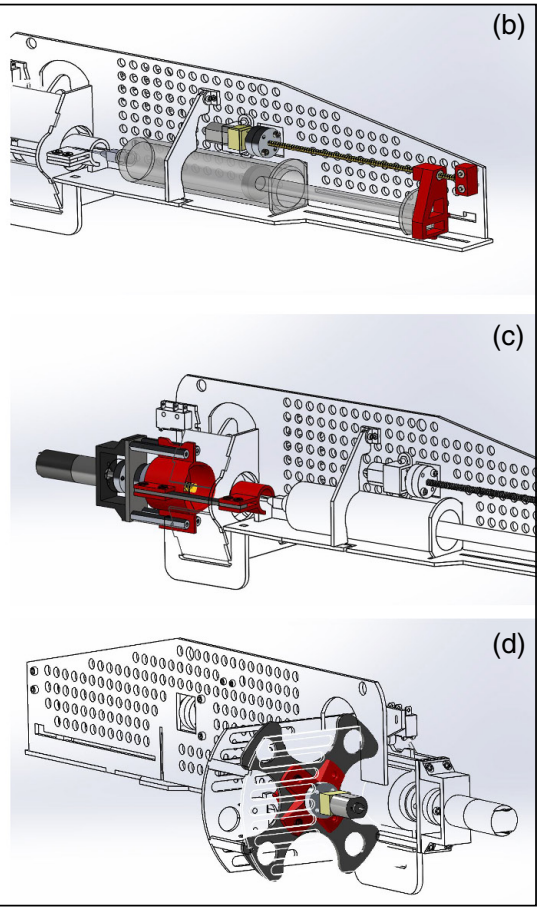

b)

Figure 4. A UAS prototype for fire ignitions (a) hovers above a recently injected and deployed flaming ball. Schematics show the lightweight motors that coordinate UAS ignitions. Shown here are the positioning mechanism (b), piercing mechanism (c), and injection mechanism (d). A narrated video of the prototype in action within a controlled setting can be viewed at http://bit.ly/22W7x1T. An animation of the UAS ignition mechanisms during operation is available at http://bit.ly/1VOI2i7.

tive management, and innovation (Garmestani and Allen 2014) are needed to account for non-stationarity (broadly described as dynamics that do not have typical behaviors over time). Legal scholars have argued for laws that foster resilience in social-ecological systems (Craig 2010; Garmestani et al. 2013) that are more adaptive (Craig and Ruhl 2014) and transformative (Chaffin et al. 2016). These laws will need to emerge if UAS are to move past the initial trial phases, and into a future where their use is embraced and encouraged.

\section{A vision for the future}

We envision swarms of UAS with mixed capabilities being seamlessly integrated into fire management operations (Figure 5). Algorithms have been initially explored to coordinate multiple, semi-autonomous UAS for the purpose of tracking a fire across a landscape and synchronizing fire suppression activities (Kumar et al. 2011). Simulations verify that UAS vehicles can be programmed to maintain flight constraints and avoid collisions while being positioned close to the advancing fire front. As a coordinated swarm, these UAS would provide advance monitoring and fire ignition capabilities, complementing the strengths of firefighters on the ground and crews operating from other vehicles. They will leverage their sensors to determine where 


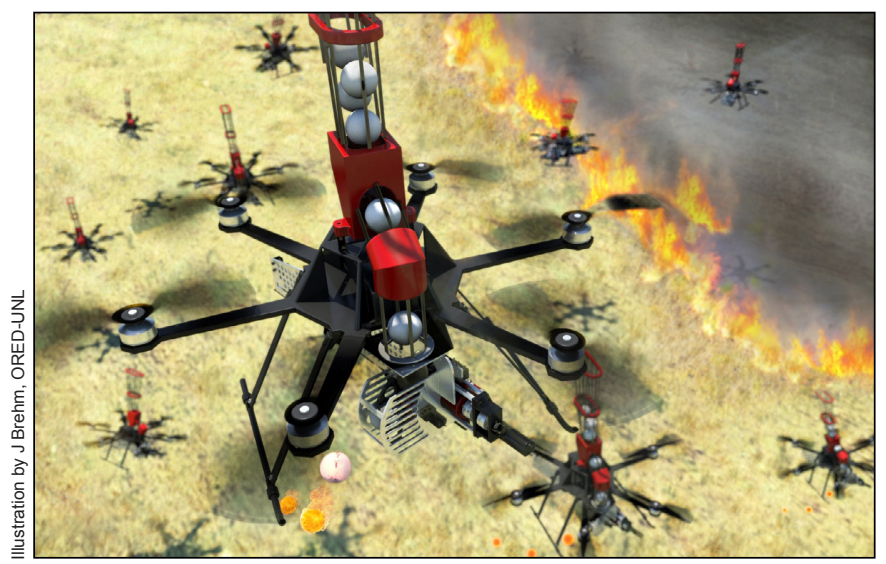

Figure 5. A vision for the future of fire management. Swarms of semi-autonomous UAS ignition vehicles carry out fire ignition techniques that are currently performed by ground crews or helicopters, requiring people to be in close proximity to flaming fire fronts.

it is safe to fly, when the conditions are appropriate for dropping ignition balls, and how best to reconfigure the swarm to optimize coverage and information flow. The UAS will also interact with members of the fire crew, broadening their situational expertise and helping to determine, for example, the optimal observing positions, given changes in the direction and rate of fire spread that may pose risks to personnel. When combined with current approaches to firefighting, UAS will complement the existing technologies, while providing new capabilities at reduced risk and cost.

This vision includes UAS as integral management components of the world's most fire dependent ecosystems, such as the Serengeti in East Africa or the Great Plains in North America. Unlike other systems threatened by increases in wildfire occurrence, size, and severity (Lohman et al. 2007), these systems are threatened by effectively irreversible regime changes resulting from the lack of fire (Gill et al. 2013; Twidwell et al. 2013b). These transitions (eg from grassland to forest) often include a strong hysteresis effect (eg Ratajczak et al. 2014), meaning that it is in humanity's interest to conserve these systems in the desired fire-maintained state rather than allowing them to undergo regime change to other ecosystem types. Despite numerous operational and institutional limitations, UAS provide one of the few technological advances seeking to meet the challenges of working with fire (sensu North et al. 2015), increasing area burned in fire-dependent ecosystems through prescriptions, and reducing situations that place fire personnel at risk.

\section{Acknowledgements}

An earlier version of this manuscript was improved by comments from K Pope and S Sundstrom. The Nebraska Cooperative Fish and Wildlife Research Unit is jointly supported by a cooperative agreement between the US
Geological Survey, the Nebraska Game and Parks Commission, the UNL, the US Fish and Wildlife Service, and the Wildlife Management Institute. Reference to trade names does not imply endorsement by the authors or the US Government. The work was funded in part by US Department of Agriculture grant \#2013-67021-20947 and a development grant from Office of Research and Economic Development-UNL (ORED-UNL). Any opinions, findings, and conclusions or recommendations expressed in this material are those of the authors and do not necessarily reflect the views of these agencies.

\section{References}

Bond WJ, Woodward FI, and Midgley GF. 2005. The global distribution of ecosystems in a world without fire. New Phytol 165: 525-38.

Bowman DM, Balch JK, Artaxo P, et al. 2009. Fire in the Earth system. Science 324: 481-84.

Bowman DM, Balch J, Artaxo P, et al. 2011. The human dimension of fire regimes on Earth. J Biogeogr 38: 2223-36.

Butler CR, O'Connor MB, and Lincoln JM. 2015. Aviation-related wildland firefighter fatalities: United States, 2000-2013. Morbidity and Mortality Weekly Report 64: 793-96.

Calkin DE, Thompson MP, and Finney MA. 2015. Negative consequences of positive feedbacks in US wildfire management. Forest Ecosystems 2: 1-10.

CASR (Civil Aviation Safety Regulations). nd. Australian Government Civil Aviation Safety Authority. Unmanned aircraft and rocket operations. www.casa.gov.au/standard-page/ casr-part-101-unmanned-aircraft-and-rocket-operations. Viewed 31 Dec 2015.

Chaffin BC, Garmestani AS, Gunderson L, et al. 2016. Transformative environmental governance. Annual Rev Environ Resour 41; doi:10.1146/annurev-environ-110615. 085817.

Craig RK. 2010. Stationarity is dead - long live transformation: five principles for climate change adaptation law. Harvard Environ Law Rev 34: 9-75.

Craig RK and Ruhl JB. 2014. Designing administrative law for adaptive management. Vanderbilt Law Rev 67: 1-87.

DellaSala DA, Williams JE, Williams CD, et al. 2004. Beyond smoke and mirrors: a synthesis of fire policy and science. Conserv Biol 18: 976-86.

Everaerts J. 2008. The use of unmanned aerial vehicles (UAVs) for remote sensing and mapping. ISPRS - Ann Photogramm Remote Sens Spatial Inform Sci 37: 1187-92.

FAA (Federal Aviation Administration). 2015. FAA announces small UAS registration rule. www.faa.gov/news/press_releases/ news_story.cfm?newsId=19856\&cid=TW378. Viewed 31 Dec 2015.

Flannigan M, Stocks B, Turetsky M, and Wotton M. 2009. Impacts of climate change on fire activity and fire management in the circumboreal forest. Glob Change Biol 15: 549-60.

Gagnon PR, Passmore HA, Slocum M, et al. 2015. Fuels and fires influence vegetation via above- and belowground pathways in a high-diversity plant community. J Ecol 103: 1009-19.

Garmestani AS and Allen CR (Eds). 2014. Social-ecological resilience and law. New York, NY: Columbia University Press.

Garmestani AS, Allen CR, and Benson MH. 2013. Can law foster social-ecological resilience? Ecol Soc 18: 37.

Gill AM, Stephens SL, and Cary GJ. 2013. The worldwide "wildfire" problem. Ecol Appl 23: 438-54.

Green OO, Garmestani AS, Allen CR, et al. 2015. Barriers and bridges to the integration of social-ecological resilience and law. Front Ecol Environ 13: 332-37. 
Hawbaker TJ, Radeloff VC, Stewart SI, et al. 2013. Human and biophysical influences on fire occurrence in the United States. Ecol Appl 23: 565-82.

Hutto RL. 2008. The ecological importance of severe wildfires: some like it hot. Ecol Appl 18: 1827-34.

IAC (Interagency Airspace Coordination). 2003. Interagency Airspace Coordination guide. www.airspacecoordination.org/ guide. Viewed 24 May 2016.

Kumar M, Cohen K, and Homchaudhuri B. 2011. Cooperative control of multiple uninhabited aerial vehicles for monitoring and fighting wildfires. J Aerospace Comp Inf Commun 8: 1-16.

Lohman DJ, Bickford D, and Sodhi NS. 2007. The burning issue. Science 316: 376.

McWethy DB, Higuera PE, Whitlock C, et al. 2013. A conceptual framework for predicting temperate ecosystem sensitivity to human impacts on fire regimes. Global Ecol Biogeogr 22:900-12.

Merino L, Caballero F, Martínez-de Dios JR, et al. 2012. An unmanned aircraft system for automatic forest fire monitoring and measurement. J Intell Robot Syst 65: 533-48.

Moritz MA, Batllori E, Bradstock RA, et al. 2014. Learning to coexist with wildfire. Nature 515: 58-66.

NIFC (National Interagency Fire Center) nd. Historical wildland fire information - federal firefighting costs (suppression only). https://www.nifc.gov/fireInfo/fireInfo_documents/SuppCosts. pdf. Viewed 6 Jun 2016.

North MP, Stephens SL, Collins BM, et al. 2015. Reform forest fire management. Science 349: 1280-81.

Oliveira SL, Campagnolo ML, Price OF, et al. 2015. Ecological implications of fine-scale fire patchiness and severity in tropical savannas of northern Australia. Fire Ecol 11: 10-31.

Ratajczak Z, Nippert JB, Briggs JM, and Blair JM. 2014. Fire dynamics distinguish grasslands, shrublands and woodlands as alternative attractors in the Central Great Plains of North America. J Ecol 102: 1374-85.

Smucker KM, Hutto RL, and Steele BM. 2005. Changes in bird abundance after wildfire: importance of fire severity and time since fire. Ecol Appl 15: 1535-49.

Tang L and Shao G. 2015. Drone remote sensing for forestry research and practices. J Forest Res 26: 791-97.

Toledo D, Sorice MG, and Kreuter UP. 2013. Social and ecological factors influencing attitudes toward the application of high- intensity prescribed burns to restore fire adapted grassland ecosystems. J Environ Manage 132: 323-28.

Topik C. 2015. Wildfires burn science capacity. Science 349: 1263.

Transport Canada. 2015. Flying a drone or an unmanned air vehicle (UAV) for work or research. www.tc.gc.ca/eng/civilaviation/standards/general-recavi-uav-2265.htm?WT.mc_ id=1zfhj\#safety. Viewed 31 Dec 2015.

Twidwell D, Fuhlendorf SD, Engle DM, and Taylor Jr CA. 2009. Surface fuel sampling strategies: linking fuel measurements and fire effects. Rangeland Ecol Manag 62: 223-29.

Twidwell D, Fuhlendorf SD, Taylor Jr CA, and Rogers WE. 2013a. Refining thresholds in coupled fire-vegetation models to improve management of encroaching woody plants in grasslands. J Appl Ecol 50: 603-13.

Twidwell D, Rogers WE, Fuhlendorf SD, et al. 2013b. The rising Great Plains fire campaign: citizens' response to woody plant encroachment. Front Ecol Environ 11: e64-e71.

Twidwell D, West AS, Hiatt WB, et al. 2016. Plant invasions or fire policy: which has altered fire behavior more in tallgrass prairie? Ecosystems; doi:10.1007/s10021-015-9937-y.

Twidwell D, Wonkka CL, Sindelar MT, and Weir JR. 2015. First approximations of prescribed fire risks relative to other management techniques used on private lands. PLoS ONE 10: e0140410.

USFS (US Forest Service). 2015. Unmanned aircraft systems. www.fs.fed.us/science-technology/fire/unmanned-aircraftsystems. Viewed 24 May 2016.

van Wilgen BW. 2013. Fire management in species-rich Cape fynbos shrublands. Front Ecol Environ 11: e35-e44.

Vincent JB, Werden LK, and Ditmer MA. 2015. Barriers to adding UAVs to the ecologist's toolbox. Front Ecol Environ 13: $74-75$.

Weir JR. 2009. Conducting prescribed fires: a comprehensive manual. College Station, TX: Texas A\&M University Press.

Werner D. 2015. Fire drones. Aerospace Am 55: 28-31.

\section{Supporting Information}

Additional, web-only material may be found in the online version of this article at http://onlinelibrary. wiley.com/doi/10.1002/fee.1299/suppinfo 